\title{
Study of Mechanical Behaviour of Coconut Shell Reinforced Polymer Matrix Composite
}

\author{
J. Olumuyiwa Agunsoye*, Talabi S. Isaac, Sanni O. Samuel \\ Department of Metallurgical and Materials Engineering, University of Lagos, Lagos, Nigeria \\ Email: *jagunsoye@unilag.edu.ng
}

Received February 21, 2012; revised March 30, 2012; accepted April 22, 2012

\begin{abstract}
The morphology and mechanical properties of coconut shell reinforced polyethylene composite have been evaluated to establish the possibility of using it as a new material for engineering applications. Coconut shell reinforced composite was prepared by compacting low density polyethylene matrix with $5 \%-25 \%$ volume fraction coconut shell particles and the effect of the particles on the mechanical properties of the composite produced was investigated. The result shows that the hardness of the composite increases with increase in coconut shell content though the tensile strength, modulus of elasticity, impact energy and ductility of the composite decreases with increase in the particle content. Scanning Electron Microscopy (SEM) of the composites (with 0\% - 25\% particles) surfaces indicates poor interfacial interaction between the coconut shell particle and the low density polyethylene matrix. This study therefore exploits the potential of agro-based waste fiber in Nigeria as an alternative particulate material for the development of a new composite.
\end{abstract}

Keywords: Coconut Shell Particles; Mechanical Properties; Composite; Morphology; Polyethylene Matrix

\section{Introduction}

Over the last thirty years, composite materials, plastics and ceramics have been the dominant emerging engineering materials. The volume and number of applications of composite materials have grown steadily, penetrating and conquering new markets relentlessly [1].

Agricultural wastes which include shell of various dry fruits, rice husks, wheat husk, straws and hemp fiber can be used to prepare fiber reinforced polymer composite for commercial use. There is great opportunity in developing new bio-based products. Natural fibers are basic interest due to their many advantages from the point of weight and fiber matrix adhesion. Existing polymers are mainly blended with different materials with the aim of cost reduction and tailor the product for specific applications.

Environmental regulations and ethical concerns have triggered the search for materials that are environmentally friendly. A pressing issue in Nigeria today, is the recycling of waste products and other agricultural by-products suitable for the invention and characterization of new materials. Annually, approximately 33 billion coconuts are harvested worldwide with only $15 \%$ of these coconuts being utilized for fibers and chips [2,3]. This suggests that there is considerable room to reduce

\footnotetext{
${ }^{*}$ Corresponding author.
}

this kind of environmental pollution and enhance the efficiency of using natural resources.

Natural lignocellulosics such as coconut shell powder (cocosnucifera) has outstanding potentials as reinforcement in plastic. Coconut shell is important filler for the development of new composites as a result of its inherent properties such as high strength and high modulus [4]. Increased in coconut shell content increases the tensile strength, Young's modulus and water absorption rate but reduces the elongation at break of coconut shell filled polyester composites [5]. Incorporating coconut shell powder reduces the damping property of $\mathrm{Pu} / \mathrm{Ps}$ biocomposite with a significant improvement in the tensile strength and tensile modulus [6]. Surface modification of coconut fiber by plasma treatment to enhance the interfacial adhesion between the coconut fibers and polylactic acid (PLA) matrix improves the mechanical properties, such as tensile strength and Young's modulus of a coconut fibers/PLA green composites fabricated using commingled yarn method [7]. Coconut shell reinforced composites showed $80 \%$ better elongation at break and $20 \%$ better Charpy impact strength than soft wood composites [8]. The natural waxy surface layer of coconut fiber provided a strong interfacial bonding between the fiber and polyethylene matrix [9]. Tensile modulus and tensile strength values increases with the increase of coconut shell particles content in a coconut shell reinforced epoxy 
resin composite, while the impact strength slightly decreased, compared to pure epoxy resin [10].

An attempt is made in this work to use the agro-based coconut shell particles as reinforcement of polyethylene matrix.

In the current study, coconut shell particle and polyethylene were used to fabricate the composites with the aim of exploring the potential of coconut shell as reinforcement for polyethylene matrix composite.

\section{Materials and Method}

The coconut shell was dried in open air and grinded into powder using a pulverizing machine, the powder was sieved in accordance with BS 1377:1990 standard. The result of the chemical analysis of the coconut shell powder is shown in Table 1. The chemical analysis of the coconut shell was done with Absorption Spectrometer (AAS)-Peckinhelma 2006 model. The particle size used was $100 \mu \mathrm{m}$.

The pelletised polyethylene waste was sun-dried and shredded in a plastic crusher machine. The coconut shell powder and the grinded pelletised (polyethylene) were blended together using a two-roll rheomixer at $50^{\circ} \mathrm{C}$ and a rotor speed of $60 \mathrm{rpm}$. The percentage of the filler in the matrix was varied from $5 \%$ to $25 \%$ to produce five different compositions. Compression of the composites was carried out with a hydraulic pressing machine for 7 minutes under controlled pressure (30 tons) at $150^{\circ} \mathrm{C}$. Each of the samples was cooled to room temperature under sustained pressure before it was removed from the press. Prior to testing, all samples were conditioned for 72 hours at a temperature of $23^{\circ} \mathrm{C} \pm 2^{\circ} \mathrm{C}$ and a relative humidity of $50 \% \pm 5 \%$. Densities of the compacted samples of known weight were determined from Equation (1). In other to determine the rate of water absorption of the samples, initially weighed dried samples were placed in a beaker with water and reweighed at an interval of $24 \mathrm{hrs}$ for 7 days (168 hrs). The water absorption rate was then determined using Equation (2).

The hardness property of samples produced was determined using Rockwell hardness tester on scale B with a $1.56 \mathrm{~mm}$ steel ball under a minor load of $3 \mathrm{~kg}$ and a major load of $60 \mathrm{~kg}$. A charpy impact machine was used to determine the impact energy of the samples. Tensile test of the composites was carried out using the Hounsfield Tensometer Tensile Machine and the morphologies of the composites observed by a Scanning Electron Microscope (SEM).

$$
\rho=\frac{m}{v}
$$

where $\rho=$ density, $m=$ mass, $v=$ volume of sample.
$\%$ Weight gained $=\frac{\text { final weight }- \text { initial weight }}{\text { initial weight }} \times 100(2)$

\section{Result and Discussion}

\subsection{Physical Properties of Coconut Shell Powder Reinforced Polymer Matrix Composite}

From Figure 1, it can be seen that the sample with the highest volume of coconut shell particles (25\%) has the most consistent rate of absorption in water. When compared with the control sample containing $0 \%$ coconut shell particles has a lower rate of absorption in water after 120 hours.

From Figure 2, as the filler increases, the porosity of the composites decreases. The water absorption is due to the hydrophilic nature of the coconut shell.

Table 1. Chemical composition of coconut shell powder in (mg/L).

\begin{tabular}{cccccc}
\hline Metal & $\mathrm{Ca}$ & $\mathrm{Fe}$ & $\mathrm{Si}$ & $\mathrm{Al}$ & $\mathrm{Mn}$ \\
\hline Composition & 28.884 & 1.882 & - & - & - \\
\hline
\end{tabular}

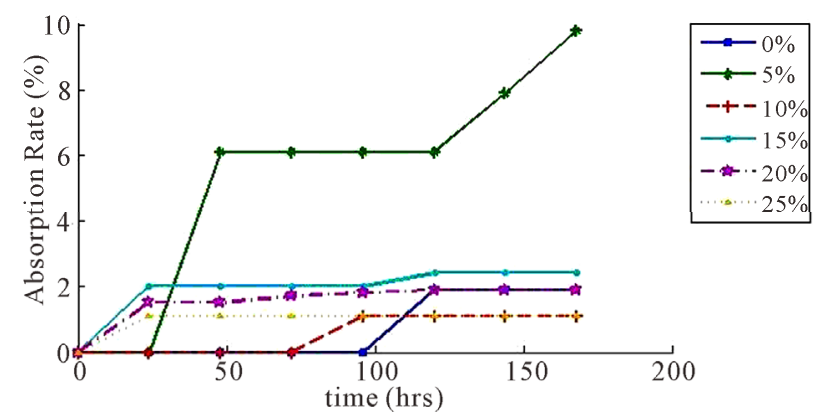

Figure 1. Effect of coconut shell particles addition on the rate of absorption of particulate coconut shell reinforced polyethylene.

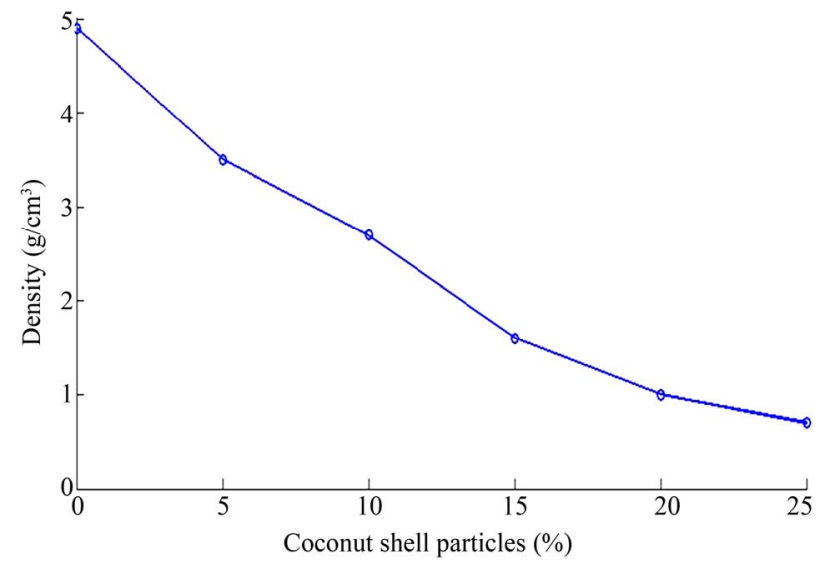

Figure 2. Effect of coconut shell particles addition on the density of particulate coconut shell reinforced polyethylene composite. 


\subsection{Mechanical Properties of Coconut Shell Powder Reinforced Polymer Matrix Composite}

The coconut shell particles have significant effect on the strength, hardness, and impact energy of the composite. From Figure 3, it can be seen that the tensile strength of the composites decrease with increase in the volume percent of the coconut shell particles within the matrix of the composite. The polyethylene composite with the highest volume fraction of filler (25\%) has the lowest strength (6.59 MPa). This may be due to imperfect interfacial bonding between the coconut shell coconut shell particles and polyethylene matrix.

As expected, the yield strength values of the composite samples decrease with increase in the volume of the coconut shell particles (See Figure 4).

From Figure 5, the ductility of the composites decreases with an increase in volume fraction of the coconut shell particles within the samples. Samples with 20\% and $25 \%$ volume fraction of coconut shell particles have the same strain value (0.9021), extrapolated from Figure 5.

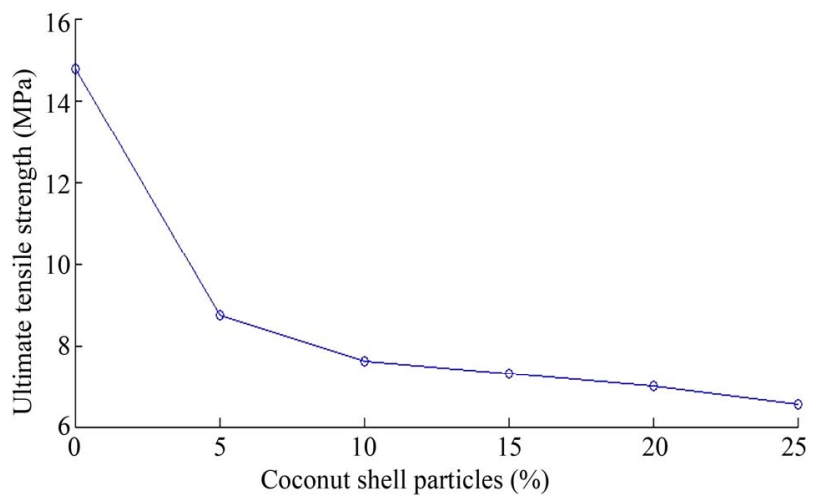

Figure 3. Effect of coconut shell particles addition on the tensile strength of coconut shell reinforced polyethylene composite.

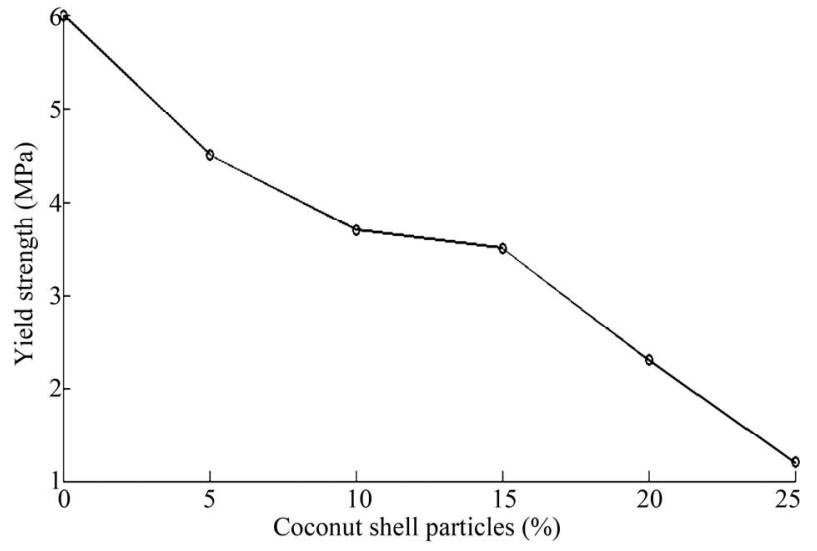

Figure 4. Effect of coconut shell particles addition on the yield strength of coconut shell reinforced polyethylene composite.
From Figure 6, it can be seen that there was a sharp decrease in the rigidity of the sample with $5 \%$ coconut shell particles within the matrix of the composite. But, as the volume fraction of the coconut shell particles increases from $5 \%$ to $25 \%$, the modulus of elasticity of the samples increases with 69.5 MPa obtained for the composite which has $25 \%$ volume fraction of coconut shell particles. This value (69.5 MPa) is higher than that of the sample without any reinforcement (i.e. $0 \%$ filler).

From Figure 7, it can be seen that the hardness of the composite increases with increase in the coconut shell

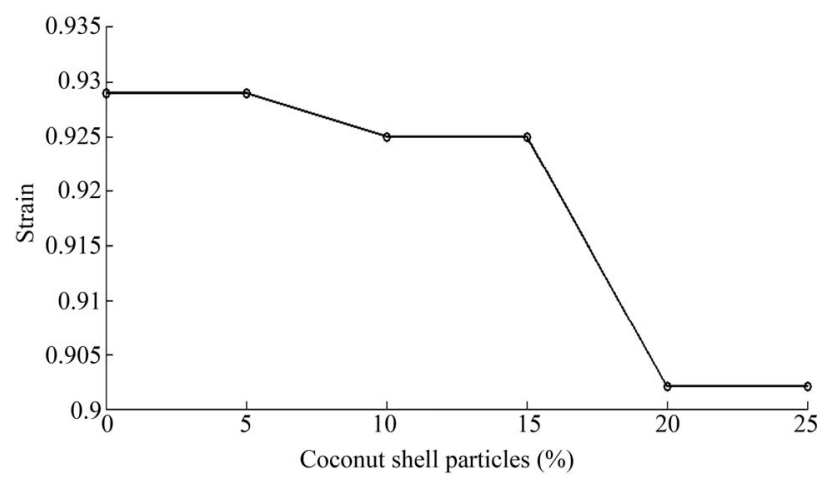

Figure 5. Effect of coconut shell particles addition on the strain of coconut shell reinforced polyethylene composite.

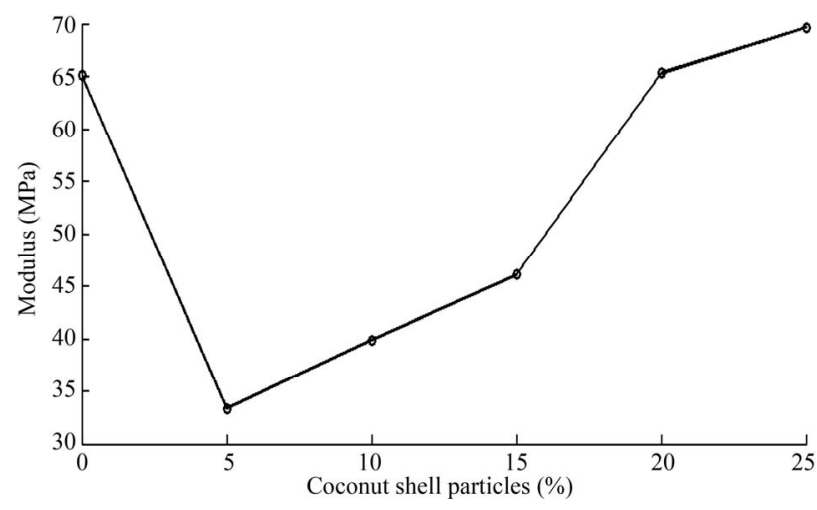

Figure 6. Effect of coconut shell particles addition on the modulus of coconut shell reinforced polyethylene composite.

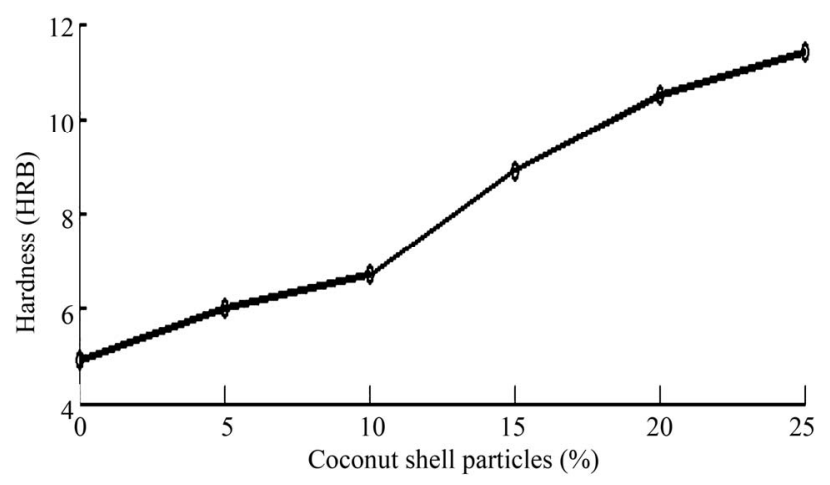

Figure 7. Effect of coconut shell particles addition on the hardness of coconut shell reinforced polyethylene composite. 
particles content within the matrix of the composite. The sample having the highest coconut shell coconut shell particles shows the highest hardness value of 11.4 HRB.

From Figure 8, the impact energy of the composite decreases with an increase in coconut shell particles content within the matrix of the polyethylene coconut shell reinforced composite. The sample with $25 \%$ volume fraction coconut shell particles in the matrix has the lowest impact energy of $1.76 \mathrm{~J}$.

\subsection{Microstructural Analysis}

The control sample represents the polyethylene matrix sample without coconut shell particles (particulate coconut shell) additions (See Plate 1). From Plates 2-6, it can be seen from the Scanning Electron Microscope results that homogeneity between the coconut shell particles and the matrix decreases with increase in the coconut shell particles content. This explains the decrease in strength with increased in the coconut shell particles content within the matrix structure of the composite. The increase in hardness is as a result of the increase in the volume percent of the coconut shell particles within matrix

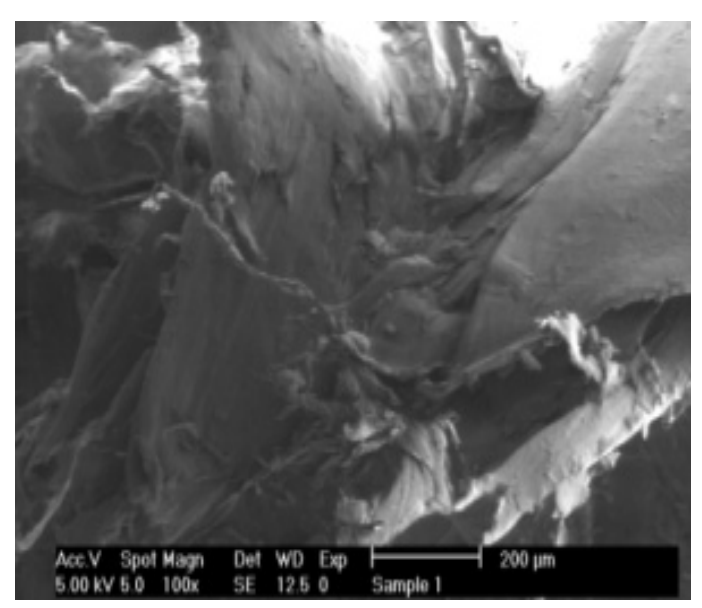

of the composite. The appearance of the gold as seen in the EDS results is indicative of the composition of the $\mathrm{Al}$ foil used as a lamination material to prevent the composite from sticking to the die mould surface during and after compaction and hot pressing using a two-roll rheomixer.

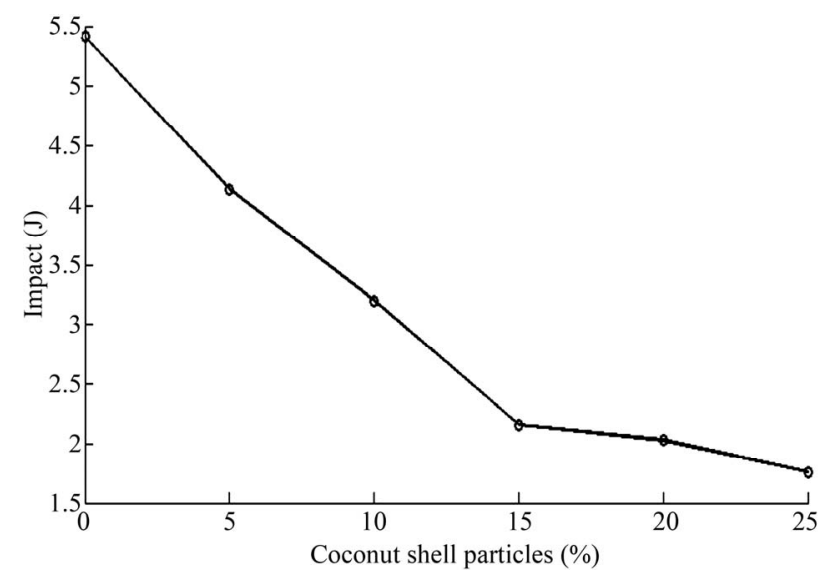

Figure 8. Effect of coconut shell particles addition on the impact of coconut shell reinforced polyethylene composite.

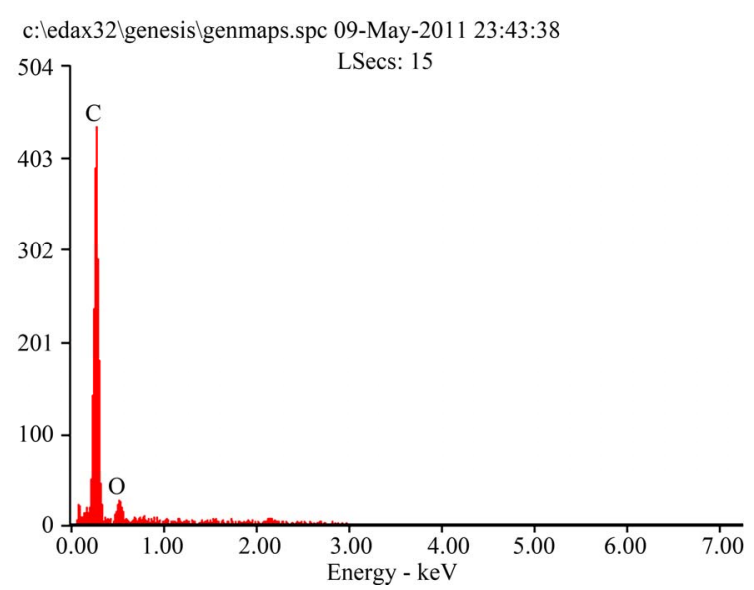

Plate 1. SEM \& EDS microanalysis of polyethylene matrix composite without coconut shell particles additions.
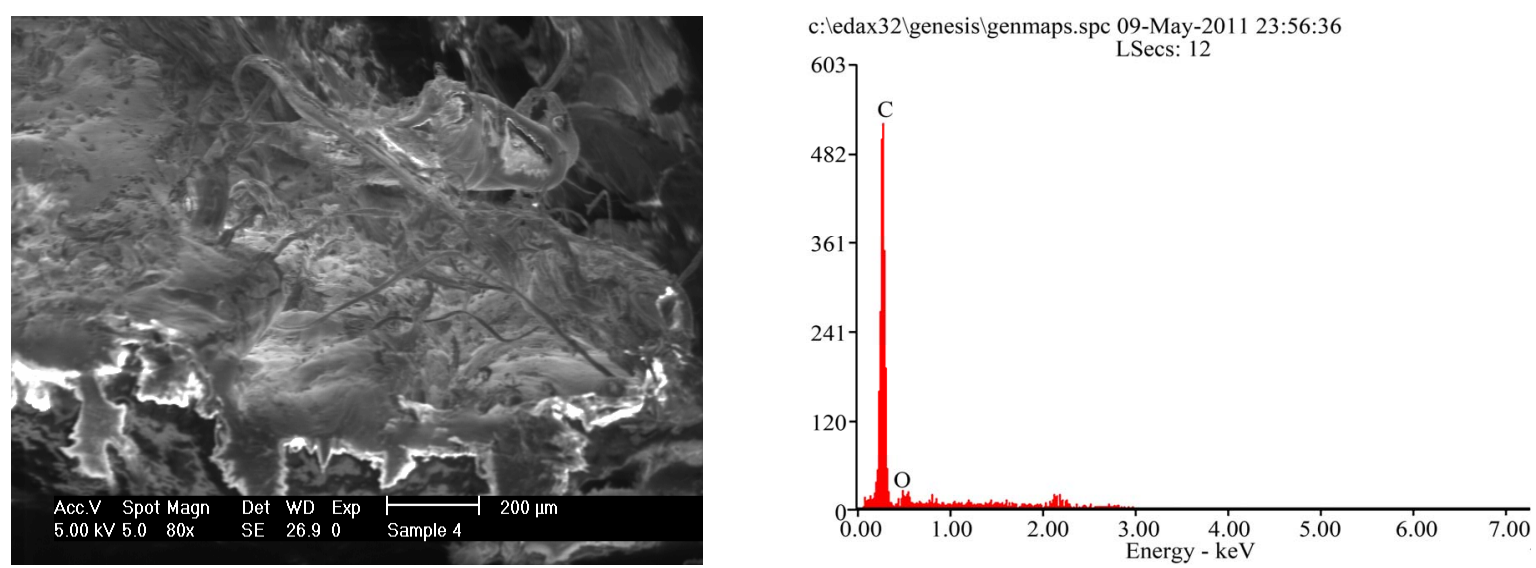

Plate 2. SEM \& EDS microanalysis of polyethylene matrix composite with $5 \%$ coconut shell particles addition. 

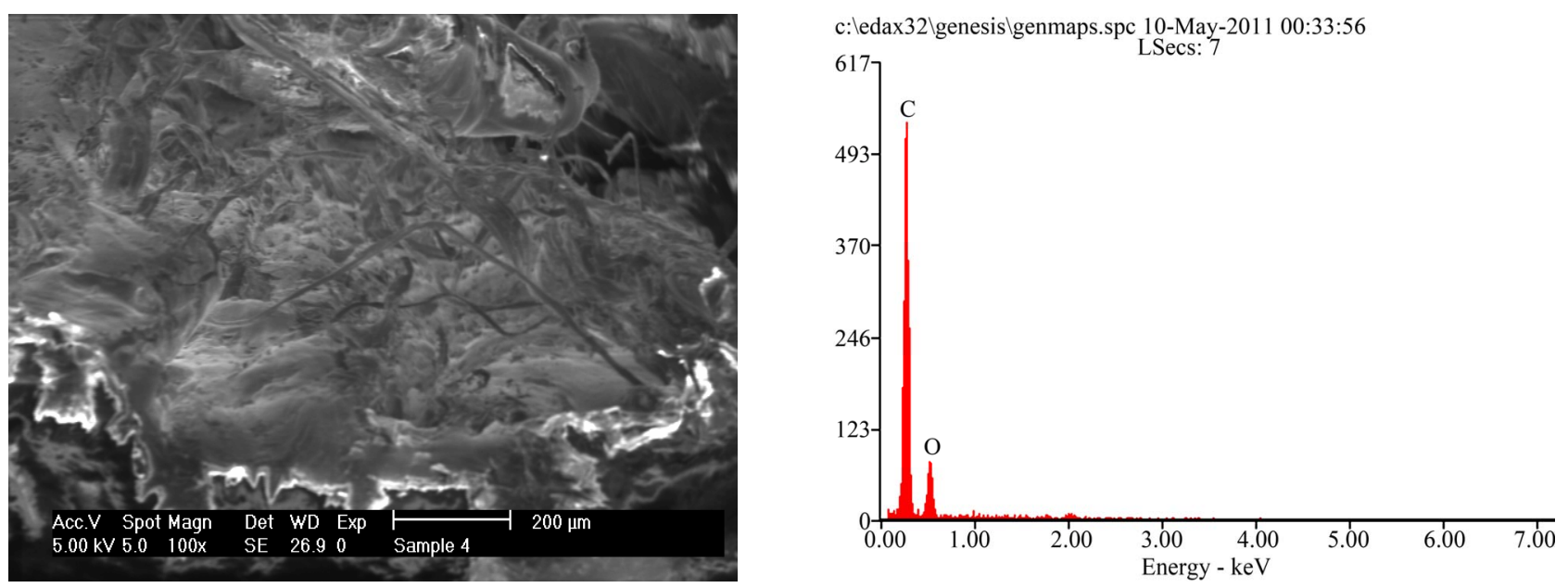

Plate 3. SEM \& EDS microanalysis of polyethylene matrix composite with $10 \%$ coconut shell particles addition.
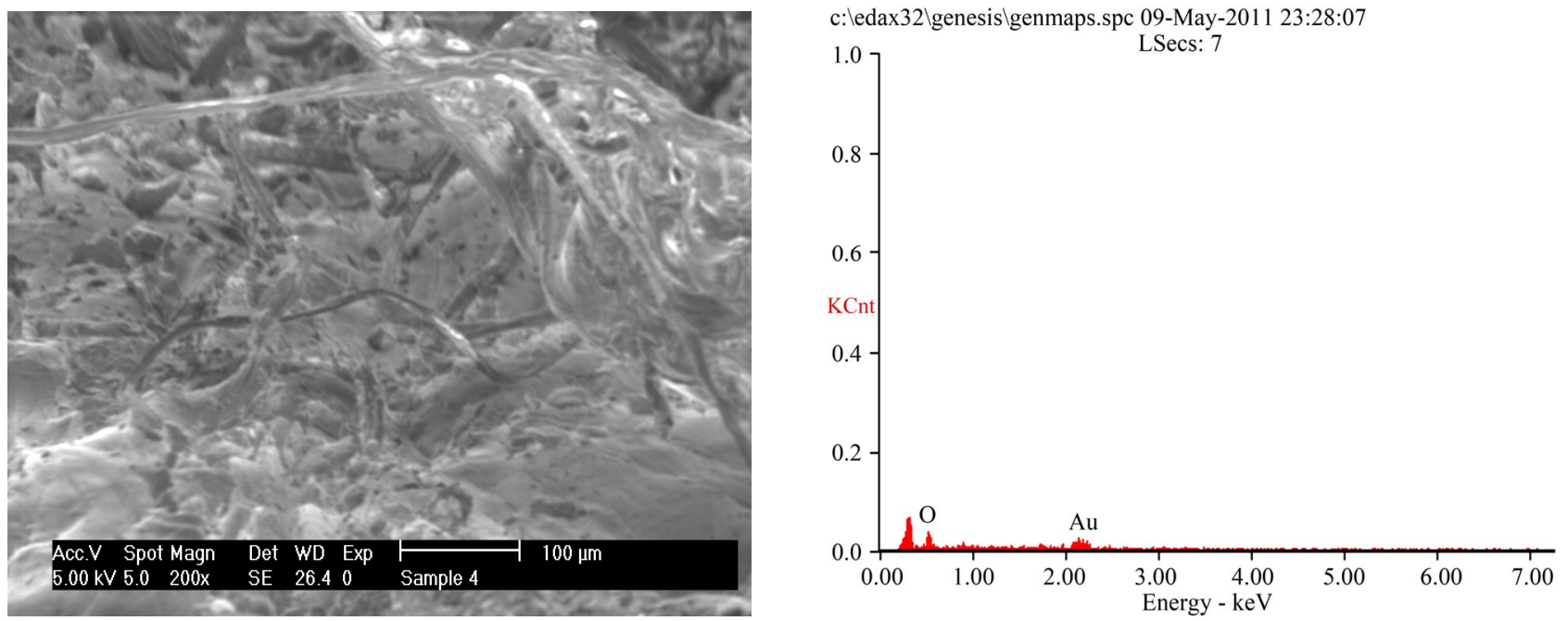

Plate 4. SEM \& EDS microanalysis of polyethylene matrix composite with $15 \%$ coconut shell particles addition.
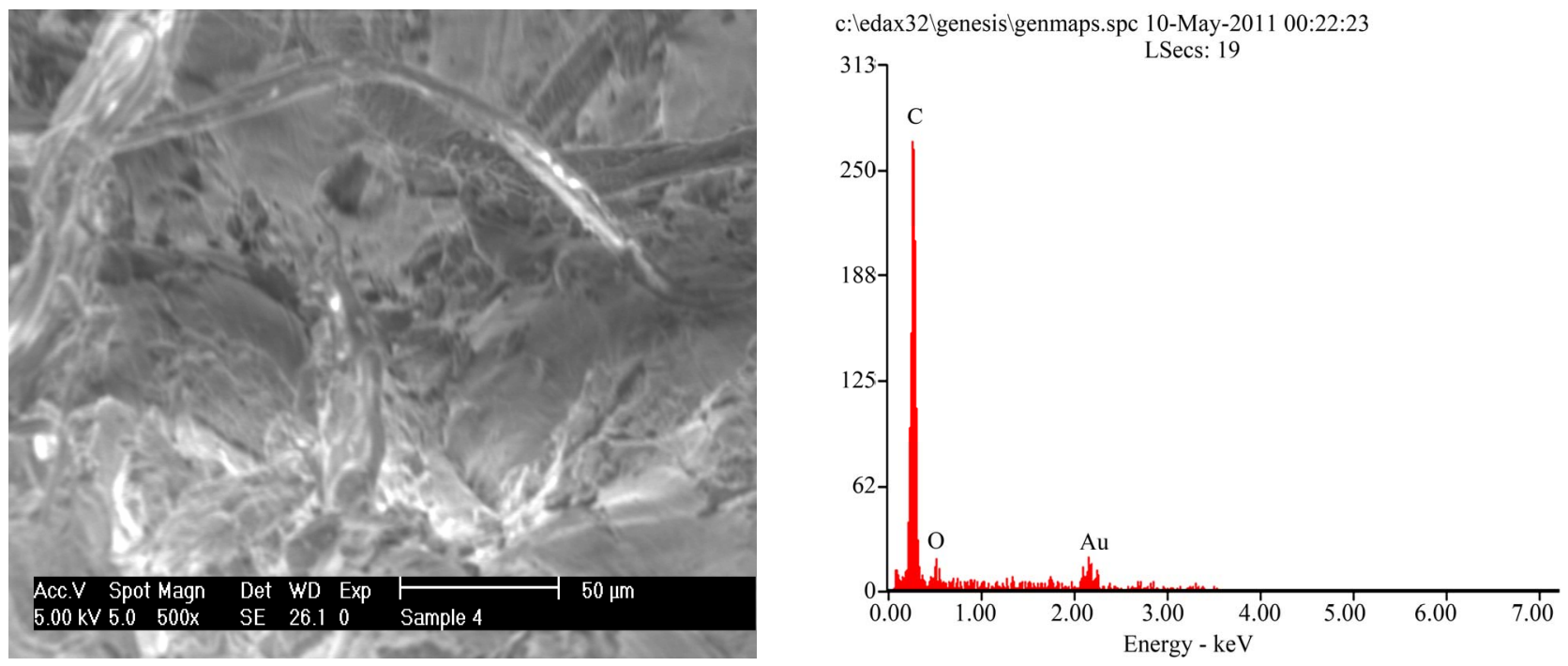

Plate 5. SEM \& EDS microanalysis of polyethylene matrix composite with $20 \%$ coconut shell particles addition. 

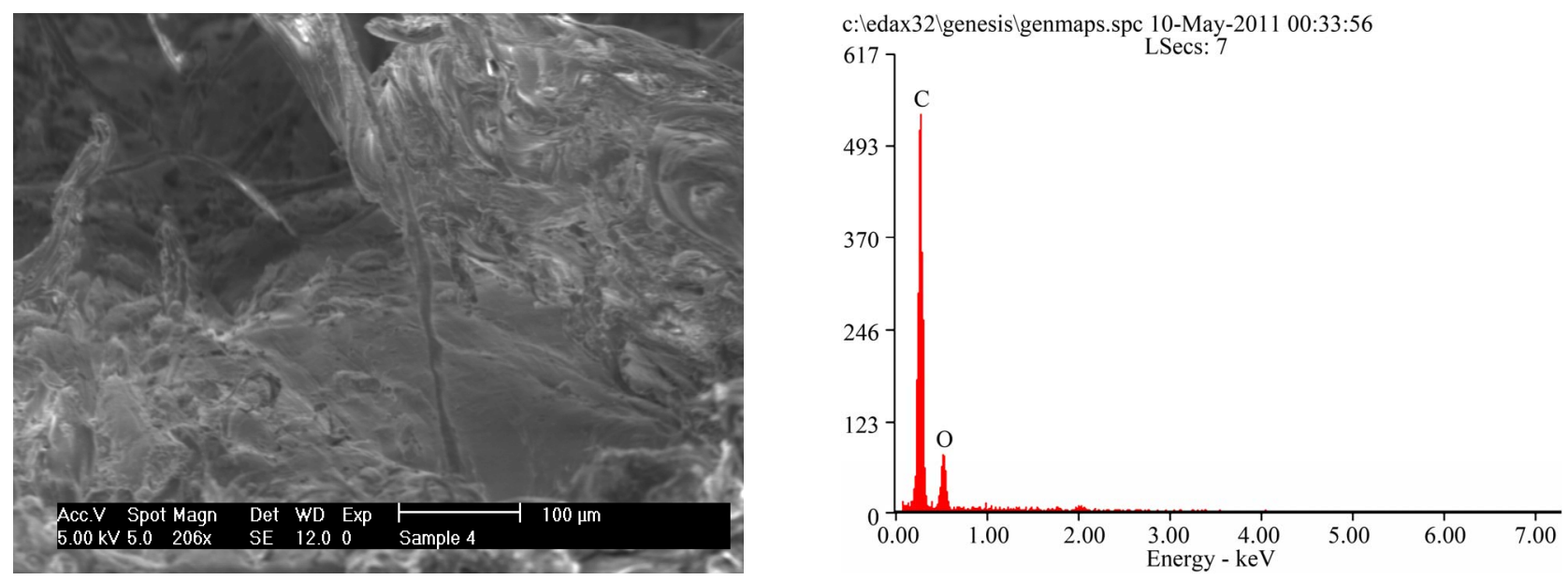

Plate 6. SEM \& EDS microanalysis of polyethylene matrix composite with $25 \%$ coconut shell particles addition.

\section{Conclusions}

From the results of the investigations and discussion, the following conclusions as been drawn:

1) The non-uniform distribution of coconut shell particle in the microstructure of the coconut shell reinforced polyethylene composite is the major factor responsible for the decrease in strength when compared with the control sample having $0 \%$ coconut shell particles (See Plates 1-6).

2) As the percentage of coconut shell particles increases, there was a corresponding decrease in porosity. This property makes the composite suitable for the application in the interior part of a motor car where materials with good hydrophobic characteristic are required. Similarly, the composite produced can be useful in other interior parts of automobile where strength is not considered a critical requirement, etc.

3) Coconut shell particles improve the hardness property of the polyethylene matrix composite. This property is an added requirement for automobile interior.

\section{REFERENCES}

[1] T. Prakash, "Processing and Characterization of Natural Fiber Reinforced Polymer Composites,” Bachelor's Thesis, National Institute of Technology, Rourkela, 2009.

[2] S. N. Monteiro, L. A. H. Terrones and J. R. M. D’Almeida, "Mechanical Performance of Coir Fiber/Polyester Composites,” Polymer Testing, Vol. 27, No. 5, 2008, pp. 591595. doi:10.1016/j.polymertesting.2008.03.003

[3] W. Wang and G. Huang, "Characterization and Utilization of Natural Coconut Fibers Composites,” Materials \& Design, Vol. 30, No. 7, 2009, pp. 2741-2744. doi:10.1016/j.matdes.2008.11.002

[4] M. Sapuan and M. Harimi, "Mechanical Properties of Epoxy/Coconut Shell Filler Particle Composites," The Arabian Journal for Science and Engineering, Vol. 28, No. 2B, 2003, pp. 171-181.

[5] S. Husseinsyah and M. Mostapha, "The Effect of Filler Content on Properties of Coconut Shell Filled Polyester Composites,” Malasian Polymer Journal, Vol. 6, No. 1, 2011, pp. 87-97.

[6] S. Roopa and M. Siddaramaiah, "Mechanical, Thermal and Morphological Behaviours of Coconut Shell Powder Filled Pu/Ps Biocomposites," Advanced Materials Research, Vol. 41, No. 14, 2010, pp. 3141-3153.

[7] Y. J. Jun, K. J. Tae, J. O. Hwa, R. Y. Jae and S. S. Young, "Thermal Stability and Flammability of Coconut Fiber Reinforced Poly(Lactic Acid) Composites,” Composites Part B: Engineering, Vol. 43, No. 5, 2011, pp. 2434-2438. doi:10.1016/j.compositesb.2011.11.003

[8] K. Andrzej and A. Abdullah, "Barley Husk and Coconut Shell Reinforced Polypropylene Composites: The Effect of Fiber Physical, Chemical and Surface Properties," Composites Science and Technology, Vol. 70, No. 5, 2010, pp. 840-846.

[9] M. Brahmakumar, C. Pavithran and R. M. Pillai, “Coconut Fiber Reinforced Polyethylene Composites: Effect of Natural Waxy Surface Layer of The Fiber on Fiber/Matrix Interfacial Bonding and Strength of Composites,” Composites Science and Technology, Vol. 65, No. 3-4, 2005, pp. 563-569.

[10] J. Sarki, S. B. Hassan, V. S. Aigbodiona and J. E. Oghenevwetaa, "Potential of Using Coconut Shell Particle Fillers in Eco-Composite Materials," Journal of Alloys and Compounds, Vol. 509, No. 5, 2011, pp. 23812385. doi:10.1016/j.jallcom.2010.11.025 